\title{
Negative correlations between anxiety-depressive symptoms and quality of life among patients on hemodialysis
}

\author{
Correlações negativas entre sintomas depressivo-ansiosos e qualidade de vida \\ em pacientes em hemodiálise
}

Juliana Bonfim do Santos', Melina Mendonça', Maria Carolina Pedalino Pinheiro", Sergio Tamail"', Ricardo Uchida"I", Luiz Antonio Miorin", Marsal Sanches ${ }^{\text {III }}$

Dear Editor,

Psychiatric symptoms such as anxiety, depressive symptoms and cognitive impairment are extremely common among patients with chronic renal failure and several studies have focused on the impact of these symptoms on the quality of life of patients on hemodialysis. ${ }^{1-5}$

In order to address this issue, we conducted a cross-sectional study in the Renal Unit of Santa Casa de São Paulo Central Hospital. The sample consisted of 23 patients with chronic renal failure on maintenance hemodialysis (10 male and 13 female; mean age $=39.3 \pm 12.8$ years; mean duration of dialysis treatment $=68.9$ months). The patients were administered the Beck Depression Inventory (BDI), Beck Anxiety Inventory (BAI), Mini-Mental Status Examination (MMSE) and World Health Organization Quality of Life Instrument (WHOQOL). The study was approved by the respective Institutional Review Board and written informed consent was obtained from all patients prior to their inclusion in the study. The data were analyzed using the Statistical Package for the Social Sciences (SPSS) version 10.0. We calculated the Spearman correlation coefficient between the scores on the anxiety and depression scales and the WHOQOL scores.

The statistical analysis revealed a moderate negative correlation between the BAI and WHOQOL scores $(\mathrm{r}=-0.39$; $\mathrm{P}<0.01)$, as well as a moderate negative correlation between the BDI and WHOQOL scores $(\mathrm{r}=-0.54 ; \mathrm{P}<0.01)$. On the other hand, no statistically significant correlation was found between the MMSE and WHOQOL scores.

Our findings seem to imply a negative correlation between anxiety and depressive symptoms and the quality of life among patients on hemodialysis. These findings are in consonance with the results of previous studies. ${ }^{1-3}$

With regard to methodological limitations, the negative results relating to quality of life and MMSE performance may be due to the small sample size. In addition, we cannot exclude the role of confounding factors, since patients who scored lower in the MMSE might have found difficulties answering the WHOQOL. Nevertheless, regardless of these methodological issues, our findings highlight the importance of adequate identification and management of psychiatric symptoms among patients with chronic renal failure.

'Medical student, Faculdade de Ciências Médicas da Santa Casa de São Paulo (FMSCSP), São Paulo, Brazil.

"MD. Psychiatric resident, Integrated Mental Health Center, Santa Casa de São Paulo, São Paulo, Brazil.

'"MD, PhD. Professor in the Department of Psychiatry, Faculdade de Ciências Médicas da Santa Casa de São Paulo (FMSCSP), São Paulo, Brazil.

"MD, PhD. Professor in the Department of Internal Medicine, Faculdade de Ciências Médicas da Santa Casa de São Paulo (FMSCSP), São Paulo, Brazil. 


\section{REFERENCES}

1. Chilcot J, Wellsted D, Da Silva-Gane M, Farrington K. Depression on dialysis. Nephron Clin Pract. 2008;108(4):c256-64.

2. Cukor D, Coplan J, Brown C, et al. Anxiety disorders in adults treated by hemodialysis: a single-center study. Am J Kidney Dis. 2008;52(1):128-36.

3. Cukor D, Coplan J, Brown C, Peterson RA, Kimmel PL. Course of depression and anxiety diagnosis in patients treated with hemodialysis: a 16-month follow-up. Clin J Am Soc Nephrol. 2008;3(6):1752-8.

4. Finkelstein FO, Wuerth D, Troidle LK, Finkelstein SH. Depression and end-stage renal disease: a therapeutic challenge. Kidney Int. 2008;74(7):843-5.

5. Levy NB. What is psychonephrology? J Nephrol. 2008;21 Suppl 13:S51-3.
Acknowledgements: This work was supported by CNPq (Conselho Nacional de Desenvolvimento Científico e Tecnológico) Foundation (Brazil)

Sources of funding: This work was supported by CNPq (Conselho Nacional de Desenvolvimento Científico e Tecnológico) Foundation (Brazil) - Grant no. 111407/2007-9

Conflicts of interest: Juliana Bonfim do Santos, Melina Mendonça, Maria Carolina

Pedalino Pinheiro, Ricardo Uchida, and Luiz Antonio Miorin have no conflicts of interest.

Marsal Sanches and Sergio Tamai are in the speakers' bureau for Astra-Zeneca

Date of first submission: December 1, 2009

Last received: February 3, 2010

Accepted: February 11, 2010

Address for correspondence:

Ricardo Uchida

Departamento de Psiquiatria da Faculdade de Medicina da Santa Casa de São Paulo Rua Major Maragliano, 241

Sao Paulo (SP) - Brasil

CEP 04017-030

Tel. (+55 11) 3466-2145

E-mail: rruchida@uol.com.br 